\title{
BioéthiqueOnline
}

\section{The Legitimacy of Prohibiting Euthanasia}

\section{Peter Gildenhuys}

Volume 4, 2015

Reçu : 9 Dec 2014; publié : 8 Oct 2015; éditeurs : Renaud Boulanger \& Charles Dupras; évaluateurs externes : Roberto Andorno \& Anonymous (peer-reviewer preferred not to be named)

URI : https://id.erudit.org/iderudit/1035512ar

DOI : https://doi.org/10.7202/1035512ar

Aller au sommaire du numéro

\section{Éditeur(s)}

BioéthiqueOnline

ISSN

1923-2799 (numérique)

Découvrir la revue

Citer cet article

Gildenhuys, P. (2015). The Legitimacy of Prohibiting Euthanasia. BioéthiqueOnline, 4. https://doi.org/10.7202/1035512ar

\section{Résumé de l'article}

John Arras se positionne contre la légalisation du suicide assisté par un médecin et celle de l'euthanasie active sur la base des coûts sociaux, qu'il anticipe comme résultat probable de cette légalisation. Arras croit que la légalisation hautement balisée du suicide assisté est le premier pas vers la légalisation de l'euthanasie active sans restriction particulière, une prédiction que je tiens pour acquis pour les besoins du raisonnement. Arras anticipe également des abus au niveau de la pratique du suicide assisté et de l'euthanasie, par les médecins, qui pourraient avoir des conséquences négatives sur de nombreux patients qui s'engagent dans ces processus. Il fait référence à ces conséquences négatives en parlant des coûts sociaux de la légalisation. Mais les coûts sociaux en jeu dans les débats publics courants sont issus de l'implication d'autres personnes que celles de l'agent qui s'engage dans l'activité controversée, plus particulièrement par celles des personnes qui ne peuvent être tenues responsables de porter le fardeau de ces coûts. Malgré certaines interprétations plausibles des prédictions d'Arras à propos de ces abus, la légalisation du suicide assisté par le médecin ou l'euthanasie ne soulève pas ce type de coûts sociaux. Pour cette raison, mais également puisque bannir l'euthanasie n'est pas équitable pour ceux qui pourraient en tirer bénéfice, les pertes calculées en utilité devraient être considérable pour justifier une interdiction.
Ce document est protégé par la loi sur le droit d'auteur. L'utilisation des services d'Érudit (y compris la reproduction) est assujettie à sa politique d'utilisation que vous pouvez consulter en ligne.

https://apropos.erudit.org/fr/usagers/politique-dutilisation/ 


\title{
The Legitimacy of Prohibiting Euthanasia
}

\author{
ARTICLE (RÉVISION PAR LES PAIRS / PEER-REVIEWED) \\ Peter Gildenhuys ${ }^{1}$
}

Reçu/Received: 9 Dec 2014

Publié/Published: 8 Oct 2015

Éditeurs/Editors: Renaud Boulanger \& Charles Dupras

Évaluateurs externes/Peer-Reviewers: Roberto Andorno \& Anonymous (peer-reviewer preferred not to be named)

2015 P Gildenhuys, Creative Commons Attribution 4.0 International License

\section{Résumé}

John Arras se positionne contre la légalisation du suicide assisté par un médecin et celle de l'euthanasie active sur la base des coûts sociaux, qu'il anticipe comme résultat probable de cette légalisation. Arras croit que la légalisation hautement balisée du suicide assisté est le premier pas vers la légalisation de l'euthanasie active sans restriction particulière, une prédiction que je tiens pour acquis pour les besoins du raisonnement. Arras anticipe également des abus au niveau de la pratique du suicide assisté et de l'euthanasie, par les médecins, qui pourraient avoir des conséquences négatives sur de nombreux patients qui s'engagent dans ces processus. II fait référence à ces conséquences négatives en parlant des coûts sociaux de la légalisation. Mais les coûts sociaux en jeu dans les débats publics courants sont issus de l'implication d'autres personnes que celles de l'agent qui s'engage dans l'activité controversée, plus particulièrement par celles des personnes qui ne peuvent être tenues responsables de porter le fardeau de ces coûts. Malgré certaines interprétations plausibles des prédictions d'Arras à propos de ces abus, la légalisation du suicide assisté par le médecin ou l'euthanasie ne soulève pas ce type de coûts sociaux. Pour cette raison, mais également puisque bannir l'euthanasie n'est pas équitable pour ceux qui pourraient en tirer bénéfice, les pertes calculées en utilité devraient être considérable pour justifier une interdiction.

\section{Mots clés}

suicide assisté par le médecin, mort assisté par le médecin, euthanasie, pente glissante, paternalisme

\section{Abstract}

John Arras argues against the legalization of physicianassisted suicide and active euthanasia on the basis of social costs that he anticipates will result from legalization. Arras believes that the legalization of highly restricted physician-assisted suicide will result in the legalization of active euthanasia without special restrictions, a prediction I grant for the sake of argument. Arras further anticipates that the practices of physician-assisted suicide and euthanasia will be abused, so that many patients who engage in these practices will lose out as a result. He refers to these losses as social costs to legalization. But the social costs at play in typical public policy debates are borne by individuals other than the agent who engages in the controversial activity, specifically by people who cannot be held responsible for enduring those costs. Even if plausible interpretations of Arras' predictions about the abuse of the practice are granted, legalization of physician-assisted suicide or euthanasia brings no social costs of this latter sort. For this reason, and also because a ban on euthanasia is unfair to those who would profit from it, the losses in utility brought about by legalization would have to be very great to justify a ban.

\section{Keywords}

physician-assisted suicide, physician-assisted death, euthanasia, slippery slope, paternalism

\section{Exonération}

Les évaluations des examinateurs externes sont prises en considération de façon sérieuse par les éditeurs et les auteurs dans la préparation des manuscrits pour publication. Toutefois, être nommé comme examinateur n'indique pas nécessairement l'approbation du manuscrit par cet examinateur. Les éditeurs de BioéthiqueOnline assument la responsabilité entière pour l'acceptation finale et la publication d'un article.

\section{Disclaimer}

Reviewer evaluations are given serious consideration by the editors and authors in the preparation of manuscripts for publication. Nonetheless, being named as a reviewer does not necessarily denote approval of a manuscript by the reviewer; the editors of BioéthiqueOnline take full responsibility for final acceptance and publication of an article. 
Affiliations des auteurs / Author Affiliations

${ }^{1}$ Department of Philosophy, Lafayette College, Easton (PA), United States

\section{Correspondance / Correspondence}

Peter Gildenhuys, gildenhp@lafayette.edu

\section{Remerciements}

Merci à George Panichas, Dan Doviak, Jukka Varelius, Isabelle Marcoux, Jocelyne St-Arnaud, Roberto Andorno, Renaud Boulanger, et les éditeurs de BioéthiqueOnline pour leurs commentaires sur les versions précédentes de ce manuscrit, qui ont vraiment permis d'améliorer l'article.

\section{Conflit d'intérêts}

Aucun déclaré

\section{Acknowledgements}

Thanks to George Panichas, Dan Doviak, Jukka Varelius, Isabelle Marcoux, Jocelyne St-Arnaud, Roberto Andorno, Renaud Boulanger, and the editors at BioéthiqueOnline for very valuable suggestions on earlier drafts that much improved the paper.

\section{Conflicts of Interest}

None declared

\section{Introduction}

In what follows, I address John Arras' opposition to physician-assisted suicide (PAS) and active euthanasia (AE), as articulated in his article, "Physician-assisted suicide: A Tragic View" [1]. Arras' opposition to PAS and AE hinges almost entirely on the potential for these practices to be abused. I argue that even if one grants Arras his suppositions about the course of social life upon legalization of PAS, his arguments fail to justify a ban of either PAS or AE.

Arras' article was published in response to arguments presented by two US Courts of Appeal: the United States Court of Appeals for the Ninth Circuit and the United States Court of Appeals for the Second Circuit [1, p.363]. Arras thought the courts took an inappropriate, "backward-looking, judicial, or constitutional" approach to the question of legalization; Arras wrote to advocate for a "forwardlooking, legislative approach" to the issue [1, p.364-65]. The chief considerations overlooked by the judicial approach consist in "social dangers" brought by legalization. Arras is worried that the judicial approach will prohibit the sorts of social checks needed to avert these social dangers [1, p.364-65].

Since Arras wrote his article, either PAS, AE or both have been legalized in several polities (the US states of Oregon, Vermont, and Washington, the Canadian province of Quebec, the Netherlands, Belgium and Luxemburg). As such, though it might be more accurate to call Arras an opponent of legality, since he would likely support repeal of laws making assisted suicide and euthanasia legal (in the US, anyhow), I will continue for convenience to present Arras as an opponent of legalization. Arras' publicly avowed views have not changed since the publication of his 1997 article.

Even though other authors have refused to support legalization of PAS and AE on the grounds that these practices are likely to be abused [2-12], I focus on Arras' stance in what follows because his opposition rests almost entirely on expected losses to patient welfare. Other authors invoke broader concerns: Leon Kass, for example, anticipates not only losses in patient welfare but also deterioration in physician-patient relations and the devaluation of human life upon legalization [10; see also 11, p.181; 13, p.35-36]. I address Arras' position mainly because he offers sustained and especially welldeveloped arguments on the basis of patient welfare, and yet I find such abuse-based arguments fall short of justifying prohibition. I also concentrate on Arras because he undertakes a number of plausible auxiliary stances, particularly ones concerning third parties who arguably could be harmed by others' engagement in PAS or AE, and these provide a definite context in which the value of abuse-based arguments can be discerned.

Arras follows Yale Kamisar in rejecting the "religious view" that killing is intrinsically different from allowing a person to die. "Certain individual actions can be morally appropriate even when the intent is simply and unambiguously to end the patient's life, and even when 'the cause' of death is simply and 
unambiguously attributable to the action of the physician" [1, p.380]. Furthermore, as Norman Cantor has pointed out with respect to Kamisar's abuse-based arguments, "Every cited hazard of physicianassisted death exists as well in the context of rejection of life-sustaining medical treatment" [14, p.1811]. Arras recognizes that the withdrawal of life-sustaining medical care (WLSC) is subject to abuse [1, p.381], so he must carefully craft an argument against PAS and AE that does not also undermine WLSC. I argue that he fails to do just that.

I begin by examining the character of Arras' arguments against PAS and AE, focusing in particular on his invocation of putative "social costs" of legalization that play a pivotal role in his "policy-oriented" approach to the question of legalization. I then argue that the sorts of losses that the legalization of euthanasia would produce are ones for which the agents that incur them are responsible. As a result, they do relatively little to justify a euthanasia ban. Moreover, bans on PAS/AE are unfair, insofar as they constrain people from profitably engaging in those practices, when by doing so they pose no threat to anyone, not even themselves. For these reasons, I argue that whatever losses in utility result from legalization would have to be very large to justify the imposition on patient autonomy that bans on PAS and AE represent.

\section{The Threat of Abuse}

Arras deploys two slippery slope arguments in his essay, but the first serves merely to raise the stakes for the second, which focuses on the abuse of PAS and AE. In his first slippery slope argument, Arras foresees an eventual slide from the legalization of physician-assisted suicide to legalized euthanasia, not only for competent people who deliberately seek it but also for incompetents who are judged to be best served by being killed according to the same sorts of "subjective" and "objective" tests that are used to justify withholding treatment from incompetents [1, p.369-70]. Arras further expects that whatever constraints on physician-assisted suicide initially accompany its legalization, such as ones requiring terminal illness or great suffering, will eventually be dropped. Arras expects the legalization of $A E$ to follow upon the heels of the legalization of PAS because "legalizing PAS, while continuing to ban active euthanasia, would serve only to discriminate unfairly against patients who are suffering and wish to end their lives, but cannot do so because of some physical impairment" [1, p.370].

For the time being, I propose to set aside incompetent patients and focus instead on the abuse of competent patients; I return to consider incompetent patients in the penultimate section of the paper. I will suppose, too, that legalization of physician-assisted suicide restricted to only some patients (e.g., ones with terminal conditions) will cause, in the long run, the legalization of euthanasia without special restrictions to particular patients with particular conditions. Recently in Belgium, euthanasia was legalized for children, the euthanasia of a prisoner was cancelled at the last minute; and people have undergone the procedure because of fears of imminent blindness and in response to a botched sex change operation [15-17]. Because I grant Arras the first slippery slope, I will focus on the practice of euthanasia in what follows, a practice that is distinct from PAS insofar as the patient's death is brought about by the physician herself who performs the intervention that ends the patient's life, for instance, by giving her patient a lethal injection [cf. 18, p.105].

It is not obvious that the slippery slope from legalized and heavily regulated PAS to legal euthanasia without special restrictions is necessarily bad, as Arras concedes [1, p.370]. The slippery slope from heavily restricted PAS to unrestricted euthanasia is important to Arras because it requires that we factor in any additional risks that would come with legalization of euthanasia without special restrictions even when considering the case for legalization of highly regulated PAS [1, p.370].

Arras' second slippery slope focuses on the possibility that the practices of PAS and AE will be abused such that "patients who fall outside the ambit of our justifiable criteria will soon be candidates for death" [1, p.370]. Arras' challenges to legalized PAS and AE are rooted in concerns about the 
quality of patient care and the potential for adverse third-party involvement. Arras is concerned that physicians and family members will exert subtly coercive influences over patients that cause them to engage in euthanasia [1, p.371]. Arras thinks that depressed patients, particularly the elderly, will request PAS or AE when they could be successfully treated for their illnesses [1, p.372]. Indeed, Arras laments that the diagnosis of depression has trailed behind progress in its treatment [1, p.372]. Finally, Arras is concerned about discrimination against the poor and minorities who will bear the brunt of the social costs associated with legalization [1, p.371-72]. In sum, Arras' concerns about the adequacy of physician care and third-party influence provide reasons to question whether legal PAS and euthanasia will be voluntary, be sought only after alternatives are thoroughly understood, and be effectively monitored. In a world in which PAS and euthanasia have been legalized, there will be people who engage in these practices who will lose out for doing so, and that harm will be disproportionate in ways that exacerbate social injustice [cf. 3, p.37-39].

So far, empirical evidence collected since Arras' publication, though ambiguous, does not provide clear support Arras' predictions. Levene and Parker find that up to half of patients requesting euthanasia/PAS may show symptoms of depression. But they note that, in the Netherlands, most patients with depression have their requests refused and that the rate of depression in cases of PAS and euthanasia is not significantly different from that of the surrounding population [19, p.210]. Ganzini et al. report that three patients given clearance for PAS by assessing physicians in Oregon had depression, though they note that it is possible that these patients "satisfied the requirements of the Death with Dignity Act if the attending physician determined that depression was present but not influencing their judgment" [20, p.974]. Battin and colleagues review of data from Oregon and the Netherlands post-legalization showed "no evidence of heightened risk of physician-assisted dying to vulnerable patients... with the exception of people with AIDS" [21, p.597]. Indeed, people who died with a physician's assistance were "more likely to be member of groups enjoying comparative social, economic, educational, professional and other privileges" [21, p.597, see also 22]. The methodology of that study has been criticized by Finlay and George, in part because Battin and colleagues leave undefined what is a vulnerable group and failed to treat some groups, such as wealthy individuals and the better educated, as potentially vulnerable groups in the context of PAS [23]. In a review of end-oflife decisions in Flanders, Chambaere and colleagues noted the under-treatment of the elderly: this population is less likely to receive intensified pain and symptom treatment in the context of palliative care. To remediate the problem, they recommend that palliative care be extended to patients with non-malignant diagnoses [24, p. 8]. But these authors are explicit that they find no evidence for the slippery slope hypothesis in elderly patients or in the general patient population [24, p.9, see also 25] Based on survey data, Onwuteaka-Philipsen and colleagues reported falling rates of ending life without an explicit patient request in the Netherlands, between 1990 and 2010 [26, p.913, see also 27]. In Belgium, Chambaere and colleagues identified 208 cases of physician-assisted deaths, 66 without an explicit patient request [28, p.896]. The same authors note that the use of life-ending drugs without explicit patient request fell from $3.2 \%$ in 1998 to $1.8 \%$ in 2007, despite the legalization of euthanasia in 2002 [28, p.900]. Moreover, the use of life-ending treatments without an explicit patient request occurred in different patient groups under different circumstances [28, p.900].

Despite the ambiguity of the evidence, I nonetheless propose to grant Arras that harmful instances of euthanasia of the sort he invokes to justify prohibition will occur as a result of legalization. Indeed, abuse is certain to occur, the frequency of which is an empirical question [29, p.173]. But to properly evaluate the weight of Arras' abuse predictions, we must assess what sorts of harms result from the abuse that Arras predicts will result from legalization.

\section{Robust Social Costs}

Arras argues that the "social cost" of legalization of PAS/AE is too great to lift the ban on these practices. The terms "social cost," "social danger," and "social risk," appear throughout Arras' essay 
when he discusses the downside of legalization. But these "social costs" are not the typical sorts of social costs that animate state prohibitions.

If Arras is right in his predictions, then lifting the euthanasia ban will entail social costs in the sense that the costs associated with legalization will be borne by members of society. Call any costs that are suffered by any member of a society social costs in the bare sense. The bare sense of social cost is the one that is used in a pure utilitarian analysis of public policy. Bare social costs matter to the level of overall utility in a society, and hence will clearly be of interest to theorists who focus on the harms that are predicted to result from legalized euthanasia, as do Arras and others $[1,2,9,30]$.

Another common use of the notion of "social cost" is to pick out costs of an act that the harmed individuals are not responsible for incurring. Call social costs of this last sort, robust social costs. While robust social costs are instances of bare social costs, the reverse is not true: not all social costs in the bare sense are social costs in the robust sense. To be robust social costs, harms must be suffered by individuals who are not responsible for suffering them. Self-directed harms typically do not count as robust social costs, since individuals are responsible for harms that they suffer as a result of their own conduct. ${ }^{1}$ This is true, anyhow, absent special circumstances, such as coercion by other parties, a special case discussed at length below.

Pollution leads to social costs in the robust sense, for example, and these can be evaluated against the benefits gained by the individual polluters and their customers: all else being equal, stricter controls on pollution are licensed by greater costs felt by those who are harmed by the toxins that polluters release. One might equally weigh the robust social costs of the legalization of firearms against the gains made by individuals who, by owning guns, possess especially effective means to protect themselves and their families.

Robust social costs are often contrasted with the "individual" benefits made by the agent, such as a polluter, who inflicts the costs [32, p.274]. But despite the name, robust social costs are really borne by individual people, for instance, by individuals who are the innocent victims of gun violence or of accidents involving others' firearms that would not have occurred had firearms been prohibited. Though suffered by individuals, robust social costs are termed "social costs" because they are diffuse. We do not know who will pay the robust social costs associated with legal firearms and exposure to pollutants; for that reason, the costs are attributed to society at large.

By way of a contrast, consider some costs and risks that are not robust social costs. Skiing and skydiving pose risks to those who engage in it, but skiers and skydivers are responsible for whatever harms they incur as a result of their activities. The harms that skiers and skydivers experience are not robust social costs. Similarly, boxers almost inevitably suffer harms by dint of engaging in combat sports, but again such losses do not count as robust social costs since boxers are responsible for their own suffering. The costs inflicted by smokers on themselves are similar: the losses suffered by smokers are ones for which they are responsible and hence do not count as robust social costs.

It is important to note that while pollution and legalized firearms produce robust social costs, this is not to say that they produce only such costs. Nor is it the case that activities such as smoking or boxing produce no robust social costs. The contrast between robust and non-robust social costs is one between types of harm, not one between types of activities. Any given activity may produce either or both sorts of harm. People may well endanger themselves by possessing firearms or damage their own health by polluting, and smokers may well harm others who are not responsible for enduring such harms, as well as themselves.

\footnotetext{
1 Sider incorporates differential weighting of self-directed and other-directed harms within a utilitarian framework [2,11-13, 30,31].
} 


\section{The Social Costs of Legalization}

I contend both that the harms Arras expects to result from legalization are not robust social costs and further that this matters enormously to our evaluation of their importance to public policy determinations. It is especially difficult to justify state prohibition of practices on the basis of social costs that are not robust.

In a liberal state, any prohibition on any activity involves an intrusion upon individual autonomy that must be justified. ${ }^{2}$ Call this the liberal burden of justification. In the rough calculus we must use to determine whether the burden of justification has been met, robust social costs are especially weighty. Robust social costs are weighty because those who suffer them are not responsible for incurring them. By contrast, when the individual who stands to be harmed by some sort of behaviour is responsible for the risks she takes or the harms she suffers, such harms do much less to meet the liberal burden of justification. We are more tolerant of harms produced by some activity, and less willing to ban the activity to prevent the harms it produces, when those harms are not robust social costs. This principle is at work in a plethora of contexts.

The aforementioned activities that are dangerous to their practitioners - downhill skiing, smoking, and boxing - would surely be banned if they posed the same threat to others that they pose to their practitioners. In a fantastical world in which the traumas experienced by downhill skiers who fall midcourse were felt not by the skiers themselves, but by other people instead, downhill ski races would not be televised; they would be banned. There is all the difference in the world between getting struck in a boxing ring that one has entered knowing the risks involved and getting struck in ordinary circumstances. Consider the lengths to which we go to constrain smokers from exposing others to toxic tobacco smoke while allowing smokers to inhale the same smoke directly themselves. Though smokers do not harm others more than they harm themselves, the harm they do to themselves is worth less, much less, to justify a constraint upon the action because the smokers are responsible for suffering the harms they cause to themselves by smoking. The great harm that smokers do to themselves does not justify keeping them from exposing themselves to cigarette toxins, though this may be partly due to the historical accident that smoking became widespread prior to the public coming to a full understanding of the risks involved. However, the harm that smokers do to others easily justifies keeping them from exposing others to cigarette toxins by means of a litany of constraints on smoking in public places. ${ }^{3}$

The point made above with respect to smoking, boxing, skiing, and the like, is surely a general one. In public policy debates, losses in welfare that are felt by individuals who responsible for facing those losses are far less weighty than losses felt by people who are not responsible for facing them. Losses on the part of individuals who are responsible for incurring them do much less to meet the liberal burden of justification than do losses felt by people who are not responsible for incurring them. Arras and other opponents of euthanasia, I contend, invoke harms that are not robust social costs in their argument against legalization, thereby dramatically raising how much disutility must result from the practice for a prohibition upon it to be legitimate.

It is worth emphasizing that the contention made here is not that conduct lacking in robust social costs can under no circumstances be banned in a liberal society. The contention instead is that social costs that are not robust do relatively little to meet the liberal burden of justification, as compared to robust social costs. Alternatively, we can say that we prize autonomy especially highly when it comes to conduct that does no harm except to people, such as the agent herself, who are responsible for incurring the harms.

\footnotetext{
${ }^{2}$ Gaus calls this the Fundamental Liberal Principle [33, p.162-166].

${ }^{3}$ Sider [34] incorporates differential weighting of self-directed and other-directed harms within a utilitarian framework.
} 
The contention that the practice of euthanasia does not produce robust social costs is not obvious. At first glance, the debate over euthanasia can seem like a classic conflict of individual vs. society, one analogous to the pollution and firearms cases. At times, Arras seems to present the debate over PAS and $\mathrm{AE}$ in these sorts of terms. He claims that his policy-oriented perspective "is crucial for adequately assessing the individual benefits and social risks involved in the proposal to legalize PAS" [1, p.375]. Later he writes that "state legislatures are in a better position than federal judges to study the social and clinical facts and come to a reasonable conclusion on the likely balance of individual benefit and social risks" [1, p.383]. One group of thinkers who explicitly present the euthanasia debate in classical individual versus society terms are the authors of the Philosophers' Brief [35]. They seek to expose just how compelling a state interest would have to be to justify a euthanasia ban by proposing the following analogies.

Consider, for example, the burden a state would have to meet to show that it was entitled to ban altogether public speeches in favour of unpopular causes because it could not guarantee, either by regulations short of an outright ban or by increased police protection, that such speeches would not provoke a riot that would result in serious injury or death to an innocent party. Or that it was entitled to deny those accused of a crime the procedural rights that the US Constitution, for example, guarantees, such as the right to a jury trial, because the security risk those rights would impose on the community would be too great. One can posit extreme circumstances in which some such argument would succeed: see, for example, Korematsu v. United States, 323 U.S., 214(1944), permitting the US to detain individuals of Japanese ancestry during the Second World War. But these circumstances would be extreme indeed, and the Korematsu ruling has been widely and severely criticized [35, p.11].

Though I am sympathetic to the stance on PAS and AE undertaken by these authors, their analogies are fundamentally flawed. A riot is costly to individuals other than the rioters, such as storeowners and passers-by, who cannot be held responsible for incurring the harms caused by the rioters. Similarly, the security risks posed by freedom for Japanese-Americans during the Second World War or by trials for accused criminals find no parallel in the ban on PAS and AE. People who engage in PAS and euthanasia do not necessarily harm others by their actions; if patients who engage in PAS/AE do harm others, such as physicians, friends, or family members, we can hold those close associates responsible for incurring the harms that they do (see below). Moreover, Arras argues that the legalization of euthanasia will be bad for its practitioners, not bad for physicians and family members; indeed, these latter folk are among those who might selfishly manipulate candidates for PAS/AE into engaging in these practices, at least according to Arras [1, p.371]. So Arras, anyway, does not contend that there are third parties who might harmed by patients who choose euthanasia.

It seems, then, that opponents of legalized PAS/AE, and especially Arras given his worries about coercers, must concede that legalization will not lead to robust social costs. This means conceding that the practices would have to produce great losses in utility to their practitioners for a ban on them to be legitimate. Still, a defender of prohibition might aim to resist the contention that PAS and AE do not produce robust social costs in a number of ways, and I turn to consider several now.

\section{Intermediaries}

One might respond that the harms resulting from euthanasia are robust social costs, since it is a physician who kills the patient; superficially, the case is similar to one party harming another, as in the pollution example. The stance being pressed here is that costs arising from voluntary euthanasia should be understood as ones for which the patient is responsible, and hence they do not count as robust social costs. Whatever harms are suffered by a patient as a result of euthanasia are caused by the patient, by means of her request, and it is for this reason that the patient is responsible for them, despite the fact that the physician serves as an intermediary. I cannot, after all, complain that the mail carrier or internet service provider has harmed me by delivering an angry message that costs me a friendship. In medicine, particularly, we prize patient autonomy at least in part because it allows 
individuals to direct their own care; and this means acknowledging that the harms or benefits that ensue from patients' autonomous decisions are ones for which the patient is responsible, even when they occur through the intermediary of a physician.

That agents may be responsible for harms they incur, even when those result from the conduct of intermediaries, explains sundry ordinary facts about what is legitimate conduct on the part of intermediaries. A request to have an organ removed by a physician makes the difference between donation and assault. The consent of the donor makes the physician's conduct legitimate, but it does so because the donor's consent makes the harms that result from the procedure ones for which the patient is responsible. ${ }^{4}$ In the context of medical research, too, what would otherwise be assault or abuse is legitimated by the free and informed consent of the research subject. Generally, a patient who autonomously consents to a medical procedure surely is responsible for whatever adversities result from competently provided care (I consider the issue of competence below).

\section{Knock-on Effects}

It might be argued that legalization would result in robust social costs because those who engage in euthanasia might harm their friends, family members or physicians. Arras does not argue this way, but Kamisar faces the charge that those who would engage in PAS are not hurting anybody else by quoting Marty and Hamel: "We are not merely a collection of self-determining individuals...we are connected to others in many different ways" [36, p.46]. Kamisar infers from these platitudes that PAS and $\mathrm{AE}$ "are social issues and matters of public policy" [5, p.113]. One might use similar grounds as a basis for affirming that euthanasia has robust social costs.

The difficulty here is that were we to generalize Kamisar's grounds for making an activity a matter of public policy, then just about anything a person does would become such. In particular, a great many medical decisions people make would become matters of public policy, including decisions to end life support, and this cannot be right, since medical decisions are among those that are the most intimate and personal.

Something should not become a matter of public policy just because it may have repercussions for other people [37]. Mill requires not just that an individual harm others but further that the individual violate a distinct and assignable obligation to them for her action to become public act "amenable to moral disapprobation in the proper sense of the term" [37, p.79]. I have been framing the matter in a similar fashion: if the harmed person is responsible for enduring some harm, even if it is caused by another person, then the harm does not count as a robust social cost. When we become close, I take responsibility for any deleterious consequences I face that result from your medical decisions. Physicians, too, are responsible for whatever losses they incur by dint of performing medical treatments they agree to perform (and no one advocates forcing physicians to comply with patients' requests for either PAS or $\mathrm{AE}$ ).

There are perhaps alternatives to these ways of drawing principled lines between matters of public and personal interest, but the most important point is this: any principle used to make these contrasts must place PAS/AE on the same side of the line as the withdrawal of life-sustaining care, along with a great many other medical decisions, for all of these may have deleterious effects on the same set of individuals other than the patient. A suggested principle for distinguishing what are matters of public policy would assuredly be judged a failure were it to deem individuals' medical decisions matters of public policy. Similarly, a criterion for picking out the harms for which people were responsible would equally be deemed a failure were it to make harmful knock-on effects on loved ones that result from private medical decisions that are the responsibility of the patient. And, once again, Arras does not consider the deleterious impact that euthanasia might have on friends and family members when setting out his argument against legalization; he argues specifically that anticipated losses in patient

${ }^{4}$ Obviously, the physician may also produce other-directed harms if she is negligent or reckless in some way. 
welfare are too great to justify legalization. Indeed, Arras is concerned that third parties, such as family members and physicians, might attempt to profit by coercing patients into engaging in PAS or $A E$ against the patients' interests.

\section{The Act of the Legislator Objection}

It may appear as though legalizing euthanasia will produce robust social costs if legalization is seen as an action taken by the legislature that ultimately leads some members of the citizenry to suffer losses in welfare. Arras, for instance, writes that "the consequentialist opponents of PAS/euthanasia are calling on society to think about the likely consequences of taking the first tentative step onto the slope" represented by legalizing PAS [1, p.371]. He equally asks us to consider "what is likely to happen when we insert a particular social practice into our existing social system" [1, p.371]. With respect to the legalization of PAS, Steinbock writes that "the question confronting society is not whether a particular individual is justified in wanting [physician-assisted suicide]. The broader question is the impact the change in law will have on society" [9, p.237]. If we are not careful in evaluating these issues, we risk misconceiving PAS and euthanasia as involving robust social costs on the grounds that the act of legalization causes other people to experience whatever losses result from the newly legalized practice.

To see how it may seem that legalization produces robust social costs, consider the change in options available to an arbitrary patient upon legalization of euthanasia. Owing to the act of the legislative body whereby euthanasia is legalized, the patient goes from being someone who lacks euthanasia or PAS as options to someone who has them, a change in status that is imposed upon the patient and one for which she is not responsible. Because we are granting that legalization will involve losses of the sort Arras contends will occur, there will be individuals who, with the broader array of options available post-legalization, do worse than they would have done with the narrower range previously available. So it seems as though the legislature has made other people worse off by means of an act of legalization.

Whatever harms appear as a result of the legalization of euthanasia should not be considered robust social costs, however, despite clearly being the causal result of the legislature's legalization of the practice. In order for some conduct to issue in robust social costs, the harms that result from the conduct must be ones for which the harmed party is not responsible. That citizens are not responsible for changing the legal status of some practice does not imply that they are not responsible for the harms they incur by engaging in the practice. To discern whether or not some losses consist in robust social costs, one must consider whether the agent who incurs the losses is responsible for incurring them, not whether the legal status of the action is one she is responsible for assigning. Indeed, were we to evaluate whether someone should be held responsible for harms they incur on the basis of whether they are caused by the decisions of a legislator, then no agent could be responsible for incurring any harms as a result of her own conduct, at least provided that her conduct was once illegal and is later no longer so. But that some conduct was at some point made legal has no bearing on whether the conduct itself involves robust social costs. Alcohol was once illegal in some Western polities, but this hardly means that all the harms attributable to alcohol consumption are robust social harms. Some of the harms that result from drinking are ones for which drinkers are responsible. Homosexual conduct was once illegal in nearly every Western polity, and people who engage in some forms of homosexual sex undertake real health risks as a result, but such harms are not automatically ones for which we do not hold consenting parties responsible just because homosexual sex used to be illegal.

\section{Coercion and Undertreatment}

The practices of PAS and AE do produce robust social costs if the patients who engage in them do not do so of their own free will. Arras claims that physicians and family member will subject patients to subtly coercive influences to engage in PAS or AE [1, p.371]. This might give the appearance that 
whatever harms result from a subtly coerced patient's engagement in euthanasia are ones for which the patient is not responsible, and hence productive of robust social costs. ${ }^{5}$ It is certainly true that were third parties to put sufficient pressure on a patient to undermine their autonomy, whatever harms result from the patient's treatment would count as robust social costs. But that physicians or family members might put sufficient pressure on a morally significant number of patients to undermine their autonomy is implausible and were the allegation true, it would spill over into other contexts.

Physicians willing to coerce patients into PAS or AE can be expected to engage in manipulative conduct quite generally. Consider merely the practice of the withdrawal of life-sustaining care. As noted earlier, "Every cited hazard of physician-assisted death exists as well in the context of rejection of life-sustaining medical treatment" [14, p.1811]. So, either physicians are already engaged in widespread abuse such that they are ultimately responsible for the early deaths of patients who would prefer maintaining life-sustaining medical treatment but are genuinely coerced into rejecting it or, much more plausibly, the vast majority of patients who refuse life-sustaining care do so out of their own will. In short, if Arras means to invoke genuine coercion of the sort that undermines patient autonomy on the part of physicians, then murder is already rampant in the medical community. If Arras means to make such an allegation, then he should do so explicitly. If not, then he should acknowledge that the subtly coercive influences he anticipates should not be counted as subversive influences that disable patient autonomy such that patients are no longer responsible for the decisions they ultimately make. The result is that whatever losses are suffered by patients who engage in euthanasia cannot be deemed robust social costs.

A parallel response is available to Arras' concerns about the quality of end of life care. Arras is concerned that "instead of vigorously addressing the pharmacological and psycho-social needs of... patients, physicians no doubt will continue to ignore, undertreat, or treat patients in an impersonal manner" [1, p.373]. He notes the lack of decent primary care for many Americans, discrimination in the delivery of pain control and other medical treatments, and misunderstandings on the part of caregivers concerned the provision of pain medication [1, p.373].

"Undertreatment" could here be evaluated with respect to two different standards, optimal care and minimally adequate care. Interpreted in the first way, Arras allegation that physicians undertreat patients is eminently plausible. But provided patient care falls somewhere in the ample breathing room between optimal care and non-negligent care, we should not hold caregivers responsible for whatever losses result from patients' healthcare decisions, even if their care is sub-optimal. Though we can imagine a patient who might have been successfully treated in an improved context of care but who instead opted for PAS or euthanasia, to do so is not necessarily to imagine someone whose losses should be counted as robust social costs.

On the other hand, if Arras means to assert that patient care is so abysmal as to fall below the standard of minimal adequacy, we could indeed hold physicians responsible for disutilities suffered by patients who request euthanasia on the grounds that their physicians are negligent and are harming patients who, owing to their physicians' negligence, cannot be held responsible for the harms they suffer as a result of their treatment. However, such an allegation of systemic physician negligence is a very strong one and loses plausibility as a result. Moreover, such an allegation would again spill over into other contexts. If there is a systematic failure of physicians to address the pharmacological and psycho-social needs of patients, and this failure is severe enough that whatever adverse outcomes result from the treatment of such patients can be laid at the feet of physician caregivers, then a great many patients are currently in a position to hold their physicians responsible for sundry adverse outcomes.

\footnotetext{
5 Similar language invoking subtle or mild coercion can be found in Washington v Glucksberg [33, p.162-166] and Pellegrino [38].
} 
Moreover, for legalization of PAS or euthanasia to involve robust social costs, it must involve costs. If patients are in fact being negligently undertreated, and many patients' pain relief is grossly inadequate, then it is hard to see how ending their lives represents a far worse alternative than continuing to live with unmanaged pain and other symptoms. Indeed, Arras expects that undertreatment will lead to "more depression, desperation, and requests for physician-assisted death from patients who could have been successfully treated" [1, p.372]. The idea seems to be that undertreatment will lead patients to seek physician-assisted death because it represents what is their best alternative, though not what should be. But if that is so, then legalization of euthanasia will not leave patients worse off even if it occurs in the context of a deficient healthcare system.

Of course, ideally, physician care would improve to the point that individuals who did engage in euthanasia would so do in the context of non-negligent medical care in which pain and other symptoms were better managed. Arras advocates for just these sorts of improvements. But in such improved circumstances, whatever losses are suffered by patients who engage in euthanasia can no longer be counted as robust social costs on the grounds that physicians are negligently under-treating their patients. In effect, I am proposing a dilemma for Arras. In contexts in which undertreatment presents a serious problem, euthanasia can be expected to offer a positive boon to patients, something which seems necessary for undertreatment to lead to an elevated number of requests for PAS/AE. In contexts in which undertreatment is not so serious, such as one in which the healthcare system is remediated such that it becomes less serious, then whatever losses are suffered by patients who engage in the practice should not be counted as robust social costs. Indeed, Arras himself acknowledges that were we to have "an equitable, effective, and compassionate health care system in place, then we might well reopen the discussion of PAS and active euthanasia" [1, p.387-88].

It goes without saying that physicians and family members should not even skirt the border between subversive and respectful influence over patients' decision-making, and similarly that caregivers should aspire to more than non-negligent caregiving, especially for disadvantaged groups, including the elderly. Notice, however, that these are general truths, having little to do with euthanasia in particular. They do, however, provide grounds for making the sorts of reforms that Arras advocates. The proponent of legalization can grant that Arras' concerns should animate changes to the training regimen of physicians, increased efforts to counter discrimination, and agitation for changes to legal institutions that undermine effective care. Indeed, this is no less true even if Arras means to make the strong contention that healthcare for patients who are liable to consider euthanasia is so poor as to be morally disreputable and a stain on the healthcare community and society more broadly.

\section{Putative Disanalogies between PAS/AE and WLSC}

That Arras' case fails to invoke robust social costs might be obscured by a putative disanalogy between the cases of euthanasia and the withdrawal of life-sustaining care (WLSC) in terms of the social consequences of legalization of each. Arras writes, following the New York Task Force, that "the social consequences of not honouring requests to forgo treatment are very different from the consequences of failing to honour requests for PAS and euthanasia" [1, p.380]. He writes later on: "While there may well be many overlapping similarities between withholding treatment and participating in PAS or euthanasia, their respective denial at the level of social policy would entail vastly different individual and social consequences" [1, p.381]. I aim to combat Arras' contention and to do so I invoke parallels between euthanasia and WLSC. My argument does not depend, however, on the assertion of a more general moral equivalency between these two practices. Instead, I seek only to rebut Arras' argument that there are important disanalogies between the practices, in particular, that the practices are disanalogous with respect to the sorts of social costs a ban on each does, or would, involve.

Arras' case for divergent social consequences rests in part on the current state of social policy: the right to forego treatment is deeply embedded in our social and medical practices while euthanasia is not. Arras also notes that fewer patients refuse life support than those that would engage in 
euthanasia [1, p.381]. But the core of Arras' case that the social consequences of legalization of euthanasia differ from those of foregoing life support does not rest on actual differences between the two practices.

Pursing the contrast between euthanasia and WLSC, Arras writes that, in the euthanasia case, those whose requests for euthanasia are denied have other options that may allow them to avoid prolonged and painful deaths, including palliative care, the opportunity to refuse life-sustaining care, physicianassisted starvation, as well as suicide by their own hand or with the covert assistance of a physician $[1$, p.380]. This remark does nothing to show that the social consequences of the denial of euthanasia and the withdrawal of life support are different, however, since patients whose requests for WLSC are denied would have the same range of options (minus, of course, the withdrawal of life support itself).

Arras goes on to assert another putative fashion in which the denial of euthanasia and WLSC are different. "Were society, systematically and as a matter of policy, to refuse to honor requests to forgo life-sustaining treatments, then everyone would have to submit to the imposition of unwanted and often invasive measures" [1, p.381]. It is not clear what Arras means here. Surely it is hyperbolic to say that "everyone would have to submit to the imposition of unwanted and often invasive measures" were we to deny patients the right to refuse life-sustaining medical treatment: plenty of people never find themselves on life support, and of those who do, plenty are never inclined to refuse. ${ }^{6}$ More likely Arras means that, were such refusals outlawed, then everyone would have to submit themselves to unwanted life-sustaining medical treatments were they to find themselves on life support and disposed to refuse. But there is no lack of a parallel to euthanasia there, since everyone would have to submit to an undesirable death were they to find themselves desirous of euthanasia and constrained from engaging in it.

A final putative reason to think the social consequences of legalized WLSC and legalized euthanasia differ is this: "Whereas the refusal to honor a request for PAS or direct euthanasia amounts to a refusal of a positive benefit or assistance, the imposition of medical treatment against one's will represents a violation of personal autonomy and physical integrity totally incompatible with the deepest meaning of our traditional respect for liberty" [1, p.381]. Arras' contrast is genuine but not germane. The question at issue is whether the state is justified in restricting individuals from engaging in PAS or AE. These practices represent a positive benefit or assistance provided by another person. But a state-enforced ban on euthanasia is not a refusal of positive benefit or assistance. An individual who refuses a patient's request to be killed is indeed refusing to assist, but the state is not refusing to assist anyone by prohibiting euthanasia. That euthanasia is a form of assistance means that any physician may refuse to comply with a patient's request for euthanasia while, by contrast, physicians must comply with a request for WLSC. This is the genuine importance of the contrast between euthanasia and WLSC. But that euthanasia is a form of assistance does not mean that the state is somehow not constraining individual autonomy by banning it or somehow constraining individual autonomy in a different sort of way than how the state constrains autonomy when banning practices that do not require a willing partner. A ban on either WLSC or euthanasia effectively keeps autonomous agents from willingly and autonomously effectuating a plan of action (having life sustaining care withdrawn, being killed), and this is true even though in only one case does the plan involve the provision of a positive benefit or assistance on the part of a non-state actor. Whether or not a practice requires a willing partner is not germane to the question of whether or not the state may legitimately restrict the autonomy of its citizens by prohibiting the practice.

It might be insisted that there remains a disanalogy between euthanasia and the withdrawal of life support insofar as undermining citizens' right to refuse life-sustaining care is a much harsher imposition than is a ban on euthanasia. Arras is certainly right that the imposition of medical treatment

\footnotetext{
${ }^{6}$ On the basis of an extensive survey, Prendergast and colleagues noted that "the median practice in 131 ICUs was to limit life support in $70 \%$ of deaths, with a median of $48 \%$ of deaths following the withholding or active withdrawal of life support" [31, p.96].
} 
against a patient's will is one of the most severe sorts of violation of individual autonomy and physical integrity imaginable. Rubenfeld suggests that rape is an especially heinous crime in that it involves an infringement upon the victim's self-possession, possession of her own body [39]; imposition of unwanted medical interventions might be deemed especially serious on similar grounds. By contrast, state constraints that disallow a patient from contracting for her death are not equally severe.

Nonetheless, it must be recognized that individual autonomy does not end at the skin. I am still being constrained when the state prevents me from entering into one or another sort of contract as I am when someone violates the physical integrity of my person: for instance, state-backed regulations on access to drugs are widely recognized as limitations to individual autonomy, ones that have become increasingly suspect in light of how they may stymie the efforts of otherwise terminally ill patients to gain access to potentially life-saving therapies [40]. We can grant, then, the disanalogy between the harshness of the imposition on autonomy produced by bans on WLSC and euthanasia. We can nonetheless maintain the key elements of the case being made here: that neither euthanasia nor WLSC produce robust social costs, and further that bans on either of these practices are the same sort of ban, ones that undermines individual autonomy in the same sort of way.

\section{The Legitimacy of Prohibiting Euthanasia}

The previous section was dedicated to arguing that PAS and euthanasia do not produce robust social costs. I considered and countered several lines of argument aimed at resisting this conclusion. I will henceforth regard it as established. This section aims to leverage that conclusion for the purposes of evaluating the legitimacy of a ban on euthanasia in liberal societies. I consider the prospects of justifying a euthanasia ban from a pure utilitarian perspective as well as a mixed perspective according to which the impact of a ban on both individual autonomy and utility matters to its legitimacy.

The conclusion that euthanasia produces no robust social costs is important because it makes a euthanasia ban patently unlike bans on conduct in which individual agents seek to pursue their own interests, where such pursuit confers costs upon members of society who are not responsible for incurring those costs. The sorts of robust social costs that result from pollution, legalized firearms, and riots do not result from the practice of euthanasia. What's more, a ban on PAS and AE is positively harmful to individuals who would not hurt anyone, even themselves, by engaging in PAS or AE. Arras explicitly recognizes the existence of patients who would profit from the availability of PAS or AE [1, p.367, see also 6].

I argued above that non-robust social costs do relatively little to meet the liberal burden of justification. Put another way, we especially prize personal autonomy when it comes to conduct that is harmful only to parties that are responsible for incurring those harms. As a result, the losses that must result from legalized euthanasia must be especially great for a ban on the practice to be justified.

I am not committed to the position that non-robust social costs can never meet the liberal burden of justification. The threat of non-robust social costs may be great enough in some cases to justify a complete ban on some acts; it is certainly great enough in other cases to justify regulation. Perhaps a very few people might profitably engage in self-enslavement or duelling, but these activities, though lacking in robust social costs, involve huge risks of substantial losses in welfare for nearly everyone who would engage in them. ${ }^{7}$ Earlier I mentioned skydiving, downhill skiing, boxing, and smoking as examples of activities that fall short of meriting prohibition. Non-robust social costs produced by such activities may not justify prohibition, but they are sometimes sufficient to warrant regulation. In Pennsylvania, skydivers must have a license and carry a backup parachute, and they are required to earn a special license for parachuting at night; these are arguably justified impositions on individual

${ }^{7}$ Duelling and self-enslavement are two examples from Callahan [30] of practices that self-determination fails to justify. 
autonomy designed to mitigate self-directed harms. Similarly, smokers must purchase cigarette packs with warnings intended to bring to mind the pernicious consequences that the activity has on their health. So self-directed harms do justify public policy interventions meant to eliminate or at least mitigate them. But in the US, smoking kills hundreds of thousands of Americans a year and we still allow it, and, without question, this is only because those people are killing themselves, rather than other people.

\section{Pure Utilitarianism}

One way to avoid the result that losses in patient welfare would have to be great to justify a ban on PAS and $A E$ is simply to determine the legitimacy of a euthanasia ban by means of a pure consequentialist analysis. Prima facie, it would seem as though consequentialism would provide the best theoretical stance to use to defend a ban on PAS/AE. This is because the pure consequentialist would not distinguish between robust and bare social costs; for the pure consequentialist, whether or not an individual is responsible for incurring some harm is simply beside the point. ${ }^{8}$ But I argue next that a pure consequentialist analysis is not very congenial to a theorist who would ban only PAS and $\mathrm{AE}$, but not WLSC; moreover, Arras must, and indeed does, recognize the value of individual autonomy as a moral consideration.

Arras often presents the issue of legalization in consequentialist terms. For instance, in criticizing the Ninth Circuit court ruling that patients have a liberty interest in PAS, Arras writes of "the very real possibility that the social and individual harms attendant upon the legalization of PAS eventually would prove disproportionate to their benefits" [1, p.383]. Moreover, states that would take the risk of legalizing PAS would "run these risks as a social experiment, i.e., to determine empirically for themselves whether more good than harm will come from legalizing PAS" [1, p.383]. Finally, Arras picks out, in his prologue, John Fletcher's secular "consequentialist" case against euthanasia as an inspiration [7]. But a pure consequentialist defense of a prohibition on PAS/AE faces at least three serious difficulties.

One serious difficulty for the consequentialist opponent of PAS/AE lies in the fact that WLSC is no less susceptible to abuse than are PAS/AE. Successful abuse-based arguments against PAS/AE threaten to commit the pure consequentialist to the illegitimacy of WLSC. The pure consequentialist might evade this threat if the patients who are candidates for WLSC are in general different from those who are candidates for PAS/AE. Arras claims that candidates for WLSC will already be generally worse off than candidates for PAS/AE [1, p.381], making the costs associated with permitting WLSC smaller per patient than the corresponding ones for PAS/AE. But it should also be recognized that candidates for WLSC will tend to be less competent in their decision making, and hence more easily influenced by selfish third parties and more prone to requesting an unnecessarily early death. People will lose less by WLSC but they will do it more often. And we should remember, too, that candidates for WLSC are not always such because they suffer from a serious and debilitating life-threatening medical condition, one which would end their lives in short order were it not for ongoing medical interventions. A candidate for WLSC may be prompted to demand it because they suffer from one condition and yet be a candidate for it because they suffer from another. Moreover, patients who are candidates for WLSC must be dramatically different from candidates for PAS/AE; otherwise the consequentialist case against PAS/AE is quite weak, with the rule permitting WLSC at best narrowly passing consequentialist scrutiny while a rule permitting PAS/AE barely fails.

There is another familiar threat to the pure consequentialist defense of Arras' stance. While a rule permitting WLSC but not PAS/AE might beat out one that permits all three, a rule that dissects the class of candidates for WLSC more finely might prove better than either on strict consequentialist grounds. A pure consequentialist who is concerned about abuse might very well find it justifiable to

\footnotetext{
${ }^{8}$ Notably, Sider [34] regards this as a flaw in the theory to be remediated.
} 
curtail the practice of WLSC, perhaps by allowing only patients with sufficiently poor prognoses to engage in it.

But perhaps the biggest difficulty with a pure consequentialist perspective is that it is frankly out of keeping with the importance of patient autonomy in contemporary medical practice. That the pure consequentialist must even consider curtailing patient rights to control their own care is probably evidence enough against the viability of a pure consequentialist position. What's more, as noted earlier, Arras himself introduces considerations of personal autonomy as grounds for maintaining the norm of WLSC [1, p.381]. Arras then must, and does, take a mixed stance in which both concerns about personal autonomy and utilitarian consequences have justificatory import in resolving moral issues.

\section{Mixed Evaluation}

According to the mixed perspective, for the prohibition on euthanasia to be justified, the positive value accorded personal autonomy must be insufficient to compensate for the negative utility that would result from permitting PAS/AE, despite being sufficient to override the cost associated with the abuse of WLSC (remember, we are assuming all three practices are abused). If the value of personal autonomy is given either too high or too low a value in our moral calculations, we will end up finding all three practices either legitimate or illegitimate. Given that the losses suffered by patients who engage in WLSC cannot at present be too great, the foregoing means that Arras must regard patient autonomy as having a middling value in debates over legalization.

But the weight that personal autonomy is afforded in policy debates is not an invariant quantity; it is a function of the sort of constraint being debated. In evaluating the importance of personal autonomy in weighing the issue of whether the liberal burden of justification has been met, we must consider how prohibitions do, or would, constrain people, and who stands to benefit and/or lose as a result of the ban. I have argued already that losses for which individuals are responsible do much less to meet the liberal burden of justification than do losses incurred by people who are in no way responsible for incurring those losses. Non-robust social costs count much less toward meeting the liberal burden of justification. Below I consider two more reasons to think autonomy should bear greater weight as a moral consideration in the case at hand, even for someone like Arras who also takes consequences into account. On the one hand, the ban constrains some people who harm no one, not even themselves. On the other hand, the ban introduces an undeserved inequality into society. These facts make the ban more difficult to justify.

Constraints may be more or less justifiable insofar as they may be more or less uneven in their application. The more people there are who are needlessly constrained by some prohibition, that is, constrained to no one's benefit, the more the prohibition is uneven. To illustrate, contrast the cases of prohibitions on firearms and limits on pollution. Some individuals constrained from owning firearms would pose no threat, or even risk, to innocent people were they allowed to possess a firearm. ${ }^{9}$ Furthermore, these individuals have something to gain from firearms possession: amusement, peace of mind, protection for themselves and their family members, etc. Other individuals constrained from owning firearms do pose a threat of harm, individuals who are inclined to criminal, or perhaps merely reckless, activity. A ban on firearms possession, then, constrains many people in order to keep some from producing harmful consequences.

By contrast, we can say that any polluter produces harmful consequences for others through elevated risks of death, disease and discomfort in the broader population. ${ }^{10}$ When we limit someone's pollution,

\footnotetext{
${ }^{9}$ Some readers may insist that all armed citizens pose a threat to the innocent. I find this implausible, but I am anyway merely using the case for illustration.

${ }^{10}$ It is not strictly speaking the case that every particle of pollutant emitted by a given polluter will actually do harm but rather that the harm caused by toxins cannot be traced to individual polluters and so all emitters must be held responsible for the damage done by the pollutants they emit in proportion to the contribution they make to overall environmental toxicity.
} 
we invade their personal liberty, but we do so on the best possible grounds: they are contributing to other people's suffering. The same is not true of a ban on firearms possession. Such a ban constrains some people not because they are a threat to others but because they happen to share the inclinations of other people who are threatening. In effect, those who would own a gun and are no threat to anyone for it and being forced to value others' interests above their own. This means, or at least it should mean, that the costs associated with legal firearms must be especially high to compensate for the loss of personal liberty suffered by those who would otherwise like to own a gun and are no threat to anyone for it. And the more people there are like this, the more costly preventable gun violence must be for a constraint against firearm ownership to be legitimate. The principle I am invoking here is this: the degree to which impositions on individual autonomy matter to the legitimacy of a constraint is a function of the degree to which the constraint is applied to individuals who do not pose a threat of harm. That is, the legitimacy of a constraint is a function of the extent to which its application is uneven.

A ban on euthanasia is uneven in just the same way as a ban on firearms is uneven. The ban on euthanasia, like the ban on firearms possession, is uneven because some of the people it constrains would engage in the practice harmlessly; indeed they stand to benefit. Some individuals would hurt no one, not even themselves, by engaging in active euthanasia. That a euthanasia ban is uneven means that the losses used to justify the ban must be that much higher, or, equivalently, that autonomy is that much more weighty a consideration in an assessment of the legitimacy of a ban on euthanasia. It is worth perhaps emphasizing here that I am not saying that uneven prohibitions cannot be justified; I am saying instead that they are harder to justify: the more uneven a restriction, the greater the losses one must marshal to meet the liberal burden of justification.

Arras' is also concerned about the impact of legalization within a broader social framework marked by entrenched inequities. The advocate of legalization might well agree with Arras that the current state of geriatric and palliative care is abysmal and that physicians routinely neglect to offer their patients the best possible care. But that the diagnosis and treatment of depression among the elderly remains unacceptable is a problem for society as a whole, or at least for those members of society who are responsible for the care of the elderly. In the name of this and other failings of our healthcare system, Arras would foist additional losses of liberty and welfare upon patients who would engage in euthanasia to their benefit and who are in no way especially responsible for these broader societal failings. Similarly, while discrimination against minority groups should be recognized as an ongoing social ill, a prohibition on euthanasia effectively singles out patients who would engage in euthanasia to their benefit and forces upon them additional losses as a result of this lamentable state of affairs. In essence, by imposing additional losses in this way, a euthanasia ban introduces an undeserved inequality into society: some are made to pay especially heavily, in terms of lost liberty and welfare, to cope with discrimination and entrenched inequalities.

It is widely, though not universally, thought that undeserved inequalities in society that result from luck are at least prima facie morally undesirable or unjust. ${ }^{11}$ In the case at hand, the undeserved inequality is the result of social policy. If undeserved inequalities that result from luck are unjust, perhaps sufficiently so as to merit compensation, then surely ones that result from social policy are similarly if not more so. Accordingly, policies that institute them should at least require additional justification for this reason.

In summary, my point is that the ban on euthanasia requires justification because it is an imposition on autonomy, and further that autonomy matters especially greatly in the evaluation of the legitimacy of this particular ban for three reasons: euthanasia does not produce robust social costs; the application of the ban is uneven; and the ban imposes an undeserved inequality, provided that it is

\footnotetext{
${ }^{11}$ Roemer writes that the general form of the egalitarian ethic held in common by a bevy of egalitarian writers, including Ronald Dworkin, Richard Arnesen, G. A. Cohen and himself, is this: "society should indemnify people against poor outcomes that are the consequences of causes that are beyond their control, but not against outcomes that are the consequences of causes that are within their control" [41, p.147].
} 
justified as a means to cope with ongoing social inequities. My point is neither that prohibitions on conduct lacking in robust social costs cannot be justified, nor that uneven impositions on autonomy cannot be justified, nor that the imposition of undeserved inequalities cannot be justified. Instead, I claim that social policies with these features are harder to justify.

Arras needs the moral weight of concerns over personal autonomy to be a middling quantity, big enough to legitimate WLSC despite its abuse, but not so big as to legitimate PAS/AE despite the abuse of these practices. But instead, we should accord personal autonomy a great value in the debate over PAS/AE, even if we take consequences into account, too, because autonomy matters especially greatly given the sort of ban with which we are concerned. I suggest that to either instate or maintain a ban on PAS/AE on the basis of concerns about patient welfare, it would take a great many patients engaging in PAS or AE as a far worse alternative than what is their next best option. Only in this way could an opponent muster sufficient losses in utility to compensate for the especially severe sort of infringement upon autonomy that is put in place by a ban on PAS and AE.

\section{Incompetents}

Early on, I chose to focus on the case of competent patients, and this decision may have struck some readers as one that stacks the deck in my favour. Indeed, Kamisar has argued that an individual who considers PAS/AE will hardly be the model of the competent decision maker [43, p.27]. Were incompetent individuals unfairly deemed competent and allowed to "decide" to engage in PAS/AE, then the ban on euthanasia would no longer be one that keeps people from incurring harms for which they are responsible. According to this vision, some of the people who will die from AE upon legalization will be incompetent patients who do not wish to die but from whom an official gesture of request for euthanasia is somehow extracted and then seized upon by zealous euthanizers as an excuse to engage in what really should be considered the killing of the innocent.

The view that PAS/AE will be used to kill incompetent people by treating them as though they were competent is not among Arras' concerns, and it is hard to square with Arras' more sober worries about subtle coercion by physicians and family members. Moreover, this possibility can be effectively countered by consideration of the practice of WLSC. If our assessments of competence are already so unreliable as to make possible the envisioned practice, then a great many individuals are at present being killed, murdered in fact, by means of the withholding of life-sustaining medical care without their true informed consent. Coercive physicians and family members have no less reason to encourage WLSC than AE; they are also presumably indifferent to how they achieve their goal of bringing about the death of patients. Indeed, if candidates for WLSC generally are worse off than patients who would pursue $A E$, then it is even more likely that incompetent patients are presently being murdered by WLSC than it is likely that candidates for euthanasia would be, upon legalization. An argument against PAS/AE that posits that life-and-death decisions are being made for incompetent patients by individuals who want to kill them is unrealistic and anyhow far too strong. In a fantasy world such as this, WLSC should be banned along with PAS/AE, at least until the posited gross improprieties with respect to assessments of competence are rectified.

It might be responded that competence is a vague notion, not the cut-and-dried affair I treat it as above. But competence assessments must issue in determinations of decision-making capacity; their function is to make an all-or-nothing classification [2, p.414]. Either such determinations are made reliably, in which case we need not worry about incompetents bring unfairly killed in a future in which euthanasia is legal, or such determinations are already being made poorly, in which case we ought at present to halt the practice of WLSC until our competence determination practices are improved. The vagueness of competence does not further the argument against PAS/AE.

Another group of patients I set aside initially were those who are incompetent and correctly recognized as such. At the foot of Arras' first slippery slope, we find ourselves killing patients we regard as incompetent on the basis of the same "subjective" and "objective" tests already used to 
make decisions about their care generally. But given Arras' broader commitments, it hard to see why this practice would be morally offensive. The act of removing incompetent patients from life-support is not intrinsically morally different, from Arras' point of view, from euthanizing them; for Arras, the problem with euthanasia lies at the policy level only. Moreover, an incompetent patient who is a candidate for euthanasia in a future society that has arrived at the bottom of Arras' first slippery slope is identical to a patient in our contemporary society who we would not treat were she to contract an easily treatable medical condition. Clearly, the lives of such individuals are not ones to which we ascribe a high value at present: we allow the vicissitudes of their contraction of treatable illnesses to determine whether they live or die. So we cannot regard the legalization of euthanasia as posing any serious threat of harm to them.

\section{Conclusion}

A critic of legalized PAS and euthanasia writes:

Our democratic societies have many laws that limit individual autonomy and choice so as to protect the larger community. These include, among many others, limits on excessive driving speeds and the obligation to contribute by way of personal and corporate income taxes. Why then should different standards on autonomy and choice apply in the case of euthanasia and PAS? [44, p.43]

That last question is rhetorical but there is a clear answer. Different standards apply in the cases of euthanasia and PAS, as compared to the case of speed limits, because those who drive excessively quickly endanger other people by doing so, people who are not responsible for incurring the costs that speeders impose. By contrast, those who engage in PAS and euthanasia risk harming no one except people who, like the patients themselves, are responsible for incurring whatever harms their conduct may produce. There is a huge difference between limits on the excessive driving speeds and curbs on PAS and AE; the former are much easier to justify than the latter. The costs associated with legalized euthanasia would have to be much greater than the costs associated with speeding for a prohibition on the former to be justified.

It should be stressed, in closing, that I have considered only Arras' argument for banning PAS and $\mathrm{AE}$, chiefly because he puts forward losses in patient welfare as justification for prohibition. Other writers deploy a broader spectrum of arguments against legalization, including ones based on anticipated deteriorations of physician-patient relations and degradations of medical culture, and these have not been addressed here. Still, the foregoing criticism of Arras' slippery slope argument should serve to undermine abuse-based arguments quite generally and thereby undermine one of the main avenues of support for the prohibition upon physician-assisted suicide and euthanasia.

\section{List of References}

1. Arras J. Physician-Assisted Suicide: A Tragic View. Journal of Contemporary Health Law \& Policy. 1997;13:361-89.

2. Kamisar Y. Some Non-Religious Views Against Proposed 'Mercy-Killing' Legislation. In: Horan DJ, Mall D, editors. Death, Dying, and Euthanasia. Frederick, Maryland: University Publications of America; 1980[1958]. p. 406-79.

3. Kamisar Y. Are Laws Against Assisted Suicide Unconstitutional? The Hastings Center Report. 1993;23(3):32-41.

4. Kamisar Y. Against Assisted Suicide - Even a Very Limited Form. University of Detroit-Mercy Law Review. 1995;735:1-17.

5. Kamisar Y. The Reasons So Many People Support Physician-Assisted Suicide - and Why These Reasons are not convincing. Issues in Law and Medicine. 1996;12(2):113-31. 
6. Kamisar Y. Physician-Assisted Suicide: The Problems Presented by the Compelling, Heartwrenching Case. The Journal of Criminal Law and Criminology. 1998;88(3):1121-46.

7. Fletcher J. Is Euthanasia Ever Justifiable? Controversies in Oncology. 1982;297.

8. Callahan D, White M. The Legalization of Physician-Assisted Suicide: Creating a Regulatory Potemkin Village. Richmond Law Review. 1996;30(1):1-83.

9. Steinbock B. The Case for Physician Assisted Suicide: Not (yet) Proven. Journal of Medical Ethics. 2005;31:235-41.

10. Snyder L, Sulmasy DP. Physician-Assisted Suicide. Annals of Internal Medicine. 2001;135:209-16.

11. Baumrin B. Physician, Stay Thy Hand. In: Battin M, Rhodes K, Silver A, editors. PhysicianAssisted Suicide: Expanding the Debate. New York: Routledge; 1998.

12. Pellegrino E. Doctors must not Kill. Euthanasia: The Good of the Patient, the Good of Society. Frederick, Maryland: University Publishing Group; 1992. p. 27-41.

13. Kass LR. Neither for Love nor Money: Why Doctors Must Not Kill. Public Interest. 1989;94:2546.

14. Cantor NL. On Kamisar, Killing, and the Future of Physician-Assisted Death. Michigan Law Review. 2004;102:1793-842.

15. Waterfield B, Marszal A. Belgian Serial Rapist Will Not Be Euthanasized. The Telegraph. Jan 6, 2015.

16. Waterfield B. Euthanasia Twins 'Had Nothing to Live for'. The Telegraph. Jan 14, 2013.

17. Waterfield B. Belgian MPs Vote to Extend Euthanasia to Children of all Ages. The Telegraph. Feb 13, 2014.

18. Varelius J. Medical Expertise, Existential Suffering and Ending Life. Journal of Medical Ethics. 2014;40:104-7.

19. Levene I, Parker M. Prevalence of Depression in Granted and Refused Requests for Euthanasia and Assisted Suicide: A Systematic Review. Journal of Medical Ethics. 2011;37:205-11.

20. Ganzini L, Goy ER, Dobscha SK. Prevalence of Depression and Anxiety in Patients Requesting Physicians' Aid in Dying: Cross Sectional Survey. British Medical Journal. 2008;337(7676):973-5.

21. Battin MP, van der Heide A, Ganzini L. Legal Physician-Assisted Dying in Oregon and the Netherlands: Evidence concerning the impact on patients in "vulnerable" groups. Journal of Medical Ethics. 2007;33:591-7.

22. Ganzini L, Nelson HD, Schmidt TA, Kraemer DF, Delorit MA, Lee MA. Physicians' Experiences with the Oregon Death with Dignity Act. The New England Journal of Medicine. 2008;8(342):557-64.

23. Finlay G, George R. Legal physician-assisted suicide in Oregon and The Netherlands: evidence concerning the impact on patients in vulnerable groups-another perspective on Oregon's data. Journal of Medical Ethics. 2011;37:171-4.

24. Chambaere K, Rietjens JAC, Smets T, Bilsen J, Deschepper R, Pasman HRW, et al. Agebased Disparities in End-of-Life Decisions in Belgium: a population-based death certificate survey. BMC Public Health. 2012;12(447).

25. Smets T, Bilsen J, Cohen J, Rurup M, Deliens L. Legal Euthanasia in Belgium: Characteristics of All Reported Euthanasia Cases. Medical Care. 2009;47(12):1-6.

26. Onwuteaka-Phlipsen B, Brinkman-Stoppelenburg A, Penning C, de Jong-Krul GJF, van Delden J, J. M., van der Heide A. Trends in End-of-Life Practices Before and After the Enactment of the Euthanasia Law in the Netherlands from 1990 to 2010: A Repeated CrossSectional Survey. Lancet. 2012;380:908-15.

27. Rietjens JAC, van der Maas PJ, Onwuteaka-Philipsen B, van Delden J, J. M., van der Heide A. Two Decades of Research on Euthanasia from the Netherlands. What Have We Learnt And What Questions Remain? Journal of Bioethical Inquiry. 2009;6:271-83. 
28. Chambaere K, Bilsen J, Cohen J, Onwuteaka-Philipsen B, Mortier F, Deliens L. Physicianassisted Deaths Under the Euthanasia Law in Belgium: A population-based survey. Canadian Medical Association Journal. 2010;182(9):895-901.

29. Rachels J. The End of Life: Euthanasia and Morality. Oxford: Oxford University Press; 1986.

30. Callahan D. When Self-Determination Runs Amok. The Hastings Center Report. 1992;22(2):52-5.

31. Pellegrino ED. Physician-Assisted Suicide and Euthanasia: Rebuttals of Rebuttals The Moral Prohibition Remains. The Journal of Medicine and Philosophy. 2001;26(1):93-100.

32. Handy S. The Road Less Driven. Journal of the American Planning Association. 2006;72(3):274-8.

33. Gaus GF. Justificatory Liberalism: An essay on Epistemology and Political Theory. New York: Oxford University Press; 1996.

34. Sider T. Asymmetry and Self-Sacrifice. Philosophical Studies. 1993;70:117-32.

35. Dworkin R, Nagel T, Nozick R, Rawls J, Scanlon T, Thomson JJ. Assisted Suicide: The Philosophers' Brief. The New York Review of Books. 1997;44:41-7.

36. Marty ME, Hamel RP. Some Questions and Answers. In: Hamel RP, editor. Choosing Death: Active Euthanasia, Religion, and Public Debate. Philadelphia: Trinity Press International; 1991.

37. Mill JS. On Liberty. Rapaport E, editor. Indianapolis, IN: Hackett Publishing Company; 1978[1859].

38. US SC. Washington v. Glucksberg. West's Supreme Court reporter. 1997;117:2258.

39. Rubenfeld J. The Riddle of Rape-by-Deception and the Myth of Sexual Autonomy. The Yale Law Journal. 2013;122(6):1372-443.

40. Lombard N. Paternalism vs. Autonomy: Steps Toward Resolving the Conflict Over Experimental Drug Access Between the Food and Drug Administration and the Terminally III. Journal of Health and Biomedical Law. 2007;3(1):163-89.

41. Roemer JE. A Pragmatic Theory of Responsibility for the Egalitarian Planner. Philosophy and Public Affairs. 1993;22(2):146-66.

42. Andersen E. What is the Point of Equality? Ethics. 1999;109(2):287-337.

43. Buchanan A, Brock DW. Deciding for Others. The Milbank Quarterly. 1986;64(Supplement 2):17-94.

44. Pereira J. Legalizing Euthanasia or Assisted Suicide: The Illusion of Safeguards and Controls. Current Oncology. 2011;18(2):38-45. 